\title{
Regioselective Thiocyanation of Aromatic and Heteroaromatic Compounds by Using Boron Sulfonic Acid as a New, Efficient, and Cheap Catalyst in Water
}

\author{
Sami Sajjadifar, ${ }^{1,2}$ and Omid Louie ${ }^{2}$ \\ ${ }^{1}$ Department of Chemistry, Faculty of Science, Ilam University, P.O. Box 69315516, Ilam, Iran \\ ${ }^{2}$ Department of Chemistry, Payame Noor University, P.O. Box 19395-4697, Tehran, Iran \\ Correspondence should be addressed to Sami Sajjadifar; ss_sajjadifar@yahoo.com
}

Received 23 December 2011; Revised 19 May 2012; Accepted 20 June 2012

Academic Editor: Marijan Kočevar

Copyright (C) 2013 S. Sajjadifar and O. Louie. This is an open access article distributed under the Creative Commons Attribution License, which permits unrestricted use, distribution, and reproduction in any medium, provided the original work is properly cited.

Highly efficient regioselective thiocyanations of indoles and $N, N$-disubstituted anilines are achieved via a green and simple protocol using boron sulfonic acid (BSA) as a new catalyst and $\mathrm{KSCN} / \mathrm{H}_{2} \mathrm{O}_{2}$ as a mild and environmentally friendly oxidant in aqueous media.

\section{Introduction}

The electrophilic thiocyanation of aromatics and heteroaromatics is an important carbon-heteroatom bond formation reaction in organic synthesis [1-3]. Thiocyanate is a versatile synthon which can be readily transferred to other functional groups such as sulfide [4-7], aryl nitrile [8], thiocarbamate [9], and thionitrile [10]. Therefore, it is important to find the new and fast methods for synthesis of thiocyanate group containing aromatic systems [11]. In view of the versatility of thiocyanate group in heterocyclic construction [3], it will be important to probe the thiocyanation of aromatic and heteroaromatic compounds. Several methods have been developed for the thiocyanation of arenes by using various reagents under certain conditions [12-21]. Yet, only a limited number of reagents, such as bromine/potassium thiocyanate (only for indoles) [18], $\mathrm{N}$-thiocyanatosuccinimide (only for 5-methoxy-2-methylindole and accompanied by two bisthiocyanates) [19], ceric ammonium nitrate (CAN) [20], acidic mont K10 clay [21], iodine/methanol, oxone [22], diethyl azodicarboxylate [23], IL-OPPh 2 [24], potassium peroxydisulfate-copper(II) [25], and $\mathrm{HCl} / \mathrm{H}_{2} \mathrm{O}_{2}$ [26] have been applied to the thiocyanation of aromatic and heteroaromatic systems. However, these methodologies suffer from one or more drawbacks such as the low availability or hard preparation of starting materials $[18,19]$, the requirement of large excess of strong oxidizing reagents, low yields for some compounds [20], and performances under certain special conditions [21]. Hence, a requirement for developing alternative synthesis routines accessible to the thiocyanation of aromatic and heteroaromatic compounds is in high demand.

There is an increasing interest in the use of environmentally benign reagents and procedures. Aqueous mediated reactions have received considerable attention in organic synthesis due to the environmentally safety reasons. Water is a desirable solvent for chemical reactions because it is safe, nontoxic, environmentally friendly, readily available, and inexpensive compared to organic solvents [27-29]. Therefore, the development of an efficient and convenient thiocyanation synthetic methodology in aqueous medium is an important research area [30, 31].

Boron sulfonic acid (BSA) as acidic catalyst was introduced by Kiasat and Fallah-Mehrjardi and used for the regioselective conversion of epoxides to thiocyanohydrins under solvent-free reaction conditions (Scheme 1) [32].

\section{Experimental}

2.1. General. Chemicals were purchased from Merck chemical company. IR spectra of the compounds were obtained on 


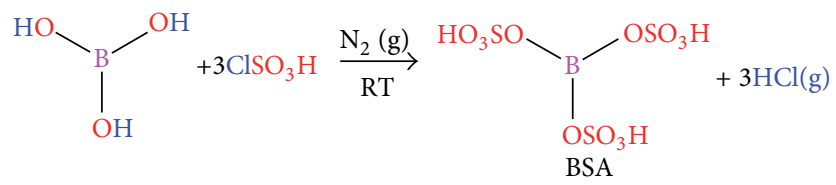

SCHEME 1: Boron sulfonic acid synthesis under nitrogen atmosphere at room temperature.

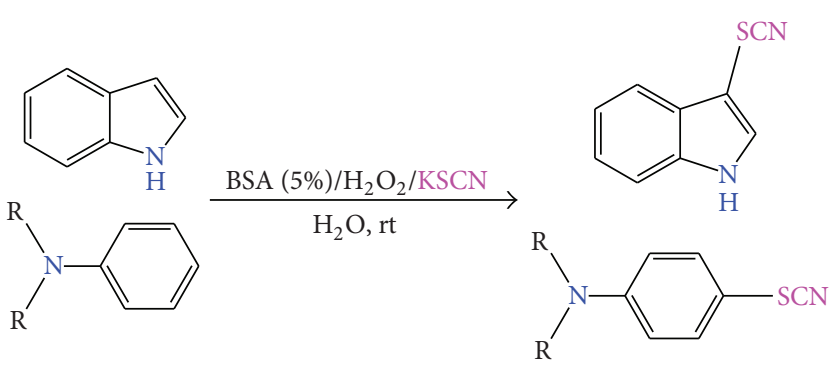

Scheme 2: The solvent effect on product yields was investigated using 1a as a substrate. Both the yields and reaction times listed in Table 1 suggest that water appears to be very favorable for thiocyanations in presence of BSA (as a strong and new catalyst).

a Shimadzu IR-435 spectrometer using a $\mathrm{KBr}$ disk. The ${ }^{1} \mathrm{H}$ NMR spectra were recorded on a Bruker AQS 300 Avance instrument at $300 \mathrm{MHz}$ in dimethyl sulfoxide (DMSO- $d_{6}$ ) as solvent and tetramethylsilane (TMS) as an internal standard. The progress of reaction was followed with TLC using silica gel SILG/UV 254 and 365 plates. All products are known compounds and were characterized by comparing the IR, ${ }^{1} \mathrm{H}$, and ${ }^{13} \mathrm{C}$ NMR spectroscopic data, and their melting points with the literature values. All yields refer to isolated products.

2.1.1. Typical Procedure for 3-Thiocyanato Indole Synthesis. A suspension of indole $1 \mathrm{a}(0.117 \mathrm{~g}, 1 \mathrm{mmol})$, potassium thiocyanate (0.294 g, $3 \mathrm{mmol}$ ), and $\mathrm{BSA} / \mathrm{SiO}_{2}(0.05 \mathrm{~g}, 5 \%)$ in $\mathrm{H}_{2} \mathrm{O}$ $(7-10 \mathrm{~mL})$ was stirred at room temperature for 5-10 $\mathrm{min}$. After that period $\mathrm{H}_{2} \mathrm{O}_{2}(30 \%, 0.45 \mathrm{~mL})$ was dropwisely added $(2-5 \mathrm{~min})$. The progress of the reaction was monitored by TLC (ethyl acetate: $n$-hexane, $1: 10$ ). After completion of the reaction, the reaction mixture was extracted with $\mathrm{CHCl}_{3}(3$ $\times 20 \mathrm{~mL}$ ), dried with $\mathrm{Na}_{2} \mathrm{SO}_{4}(5 \mathrm{~g})$ for $20 \mathrm{~min}$, filtered, and chloroform removed. Yield $0.167 \mathrm{~g}$ (96\%); dark brown solid; $\mathrm{mp} 71-73^{\circ} \mathrm{C}(\mathbf{1 b})[2,22,33]$. FT-IR $(\mathrm{KBr}):, v\left(\mathrm{~cm}^{-1}\right) 2159$, 3289; ${ }^{1} \mathrm{H}$ NMR (FT-300 MHz, $\mathrm{CDCl}_{3}$ ): $\delta$ (ppm) $8.87(1 \mathrm{H}, \mathrm{br}$ s, NH), $7.83(1 \mathrm{H}, \mathrm{d}, J=8.8 \mathrm{~Hz}), 7.46-7.23(4 \mathrm{H}, \mathrm{m}) ;{ }^{13} \mathrm{C} \mathrm{NMR}$ $\left(75 \mathrm{MHz}, \mathrm{CDCl}_{3}\right): \delta$ (ppm) 136.06, 131.22, 127.66, 123.83, $121.87,118.65,112.24$, and 91.76 .

2.1.2. Preparation of Boron Sulfonic Acid (BSA) [26, 32]. A $50 \mathrm{~mL}$ suction flask was equipped with a constant pressure dropping funnel. The gas outlet was connected to a vacuum system through an adsorbing solution (water) and an alkali trap. Boric acid $(1.55 \mathrm{~g}, 25 \mathrm{mmol})$ was charged in the flask and chlorosulfonic acid $(8.74 \mathrm{~g}$, ca. $5 \mathrm{~mL}, 75 \mathrm{mmol}$ in $5 \mathrm{~mL}$ $\mathrm{CH}_{2} \mathrm{Cl}_{2}$ ) was added dropwise over a period of $1 \mathrm{~h}$ at room temperature under $\mathrm{N}_{2}$ gas. $\mathrm{HCl}$ evolved immediately. After completion of the addition, the mixture was shaken for
85 min, while the residual $\mathrm{HCl}$ was eliminated by suction. The mixture was washed with diethyl ether to remove the unreacted chlorosulfonic acid $\left({ }^{1} \mathrm{H}\right.$ NMR spectrum of BSA in acetone- $d_{6}$ showed absorption at $12.22 \mathrm{ppm}$ ) and then $14.4 \mathrm{~g}$ $\mathrm{SiO}_{2}$ was added and mixed. Finally, dried and a grayish solid material was obtained in $95.6 \%$ yield $(21.6 \mathrm{~g})$.

\section{Results and Discussion}

The thiocyanation was investigated at various conditions. In the absence of BSA, reaction was not accomplished, but in the presence of $5 \%$ BSA $(0.05 \mathrm{~g}$ BSA equal $0.15 \mathrm{mmol}$ $\mathrm{H}^{+}$) the reaction took place with best result. We have found that BSA is active as a catalyst towards the thiocyanation of aromatic and heteroaromatic compounds using $\mathrm{H}_{2} \mathrm{O}_{2}$ as an oxidant (Scheme 2). To identify optimal conditions for the synthesis of aryl thiocyanates, we began with an investigation of the conversion of indole into the corresponding indole thiocyanate using $\mathrm{BSA} / \mathrm{H}_{2} \mathrm{O}_{2} / \mathrm{KSCN}$ in water as a model reaction (Scheme 2 ).

The stoichiometry of the reactants was also varied. A ratio of $1: 4: 3$ (indole: $\mathrm{H}_{2} \mathrm{O}_{2}: \mathrm{KSCN}$ ) was found to be the most suitable, and decreasing the amount of $\mathrm{H}_{2} \mathrm{O}_{2}$ or potassium thiocyanate increased the reaction time and lowered the yield.

The scope of this reaction was further examined using various arenes under optimized conditions (Table 2).

As shown in Table 2, indole and electron-rich indoles gave the desired products in excellent yields (Table 2, entries 1-3). Also, electron-deficient indoles such as 5-bromoindole reacted with potassium thiocyanate and $\mathrm{BSA} / \mathrm{H}_{2} \mathrm{O}_{2}$ to afford the corresponding 5-bromo-3-thiocyanatoindole in good yield, but required longer reaction time (Table 2, entry 4). This observation can be attributed to the lower electron density of such substrates. The lower yield is probably attributed to the steric hindrance of 2-substituted indole (Table 2, entry 3 ). The addition was highly regioselective 


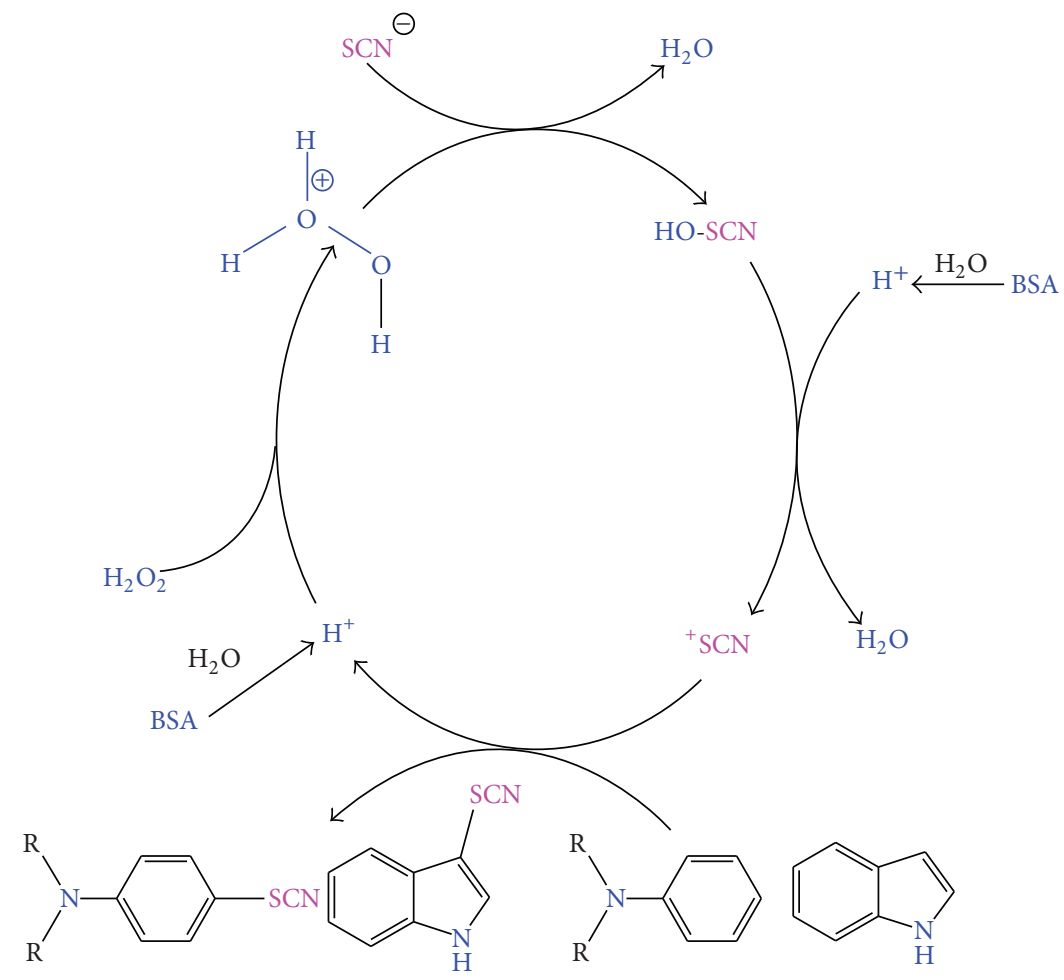

SCHEME 3: The proposed mechanism for the thiocyanation of indoles and N,N-dialkylanilines.

TABLE 1: Solvent effects on the thiocyanation of $\mathbf{1 a}$.

\begin{tabular}{lcc}
\hline Solvent & Time $(\mathrm{h}, \mathrm{min})^{\mathrm{a}}$ & ${\text { Yield }(\%)^{\mathrm{b}}}^{\mathrm{a}}$ \\
\hline Water & $00: 05$ & 98 \\
Acetonitrile & $01: 20$ & 80 \\
Tetrahydrofuran & $02: 00$ & 73 \\
Dichloromethane & $08: 00$ & 70 \\
Carbon tetrachloride & $12: 00$ & 47 \\
Ethanol & $00: 30$ & 89 \\
\hline
\end{tabular}

"The reaction time.

${ }^{\mathrm{b}}$ Isolated yield of the products after column chromatography.

occurring at the 3-position of the indole ring [25].Various $\mathrm{N}, \mathrm{N}$-disubstituted aromatic amines were converted into the respective 4-thiocyanato amines in high to excellent overall yields (Table 2, entries 5-10). The reactions were clean and the products were obtained with high-paraselectivity (Table 2, entries 9, 10). However, in the case of parasubstituted amine, ortho-thiocyanation did not occur (Table 2, entry 14).

When indoline was used as a substrate, the reaction was not complete (Table 2, entry 11). The same result was shown for 1,2,3,4-tetrahydroquinoline (Table 2, entry 12) and 1phenylpiperazine (Table 2, entry 13). On the other hand, $N, N$-4-trimethylaniline, $o$-methylaniline, anisole, pyrrole, acetanilide, imidazole, pyrazine, and pyrrole-3-carbaldehyde
(Table 2, entries 14-21) did not react with potassium thiocyanate and $\mathrm{BSA} / \mathrm{H}_{2} \mathrm{O}_{2}$ to afford the corresponding derivatives.

In comparison with other reported methods using other reagents which require refluxing conditions, the assistance of ultrasonic irradiation, toxic solvent, or oxidant, this method works under milder and greener reaction conditions.

The proposed reaction mechanism is shown in Scheme 3. In the first step, $\mathrm{H}_{2} \mathrm{O}_{2}$ reacts with $\mathrm{BSA}(\mathrm{H}+)$ to presumably in situ form hydrogen peroxonium ion $\left(\mathrm{H}_{3} \mathrm{O}_{2}{ }^{+}\right)$[34]. We have shown that the counter ion of an acid did not have any role in the course of the reaction and $\mathrm{H}_{2} \mathrm{SO}_{4}$ acts the same as $\mathrm{HCl}$. Subsequently, reaction of hydrogen peroxonium ion with $\mathrm{SCN}^{-}$generates HOSCN, which is in the presence of $\mathrm{H}^{+}$ able to produce thiocyanium ion ${ }^{+} \mathrm{SCN}^{35}$ and $\mathrm{H}_{2} \mathrm{O}$. In the last step of the reaction electrophilic substitution of thiocyanium ion ${ }^{+} \mathrm{SCN}$ with indole will generate the corresponding indole thiocyanate.

\section{Conclusions}

We have developed an efficient, simple, and green thiocyanation of aromatic and heteroaromatic compounds using $\mathrm{BSA} / \mathrm{H}_{2} \mathrm{O}_{2} / \mathrm{KSCN}$ in water as solvent, which takes place with high regioselectivity. This procedure offers advantages such as simple workup, short reaction time, low cost of reagents, mild reaction conditions, and clean formation of the desired products in high yields. 
TABLE 2: Substrate scope in the thiocyanation reaction of arenes using $\mathrm{KSCN} / \mathrm{BSA} / \mathrm{H}_{2} \mathrm{O}_{2}$ [26].

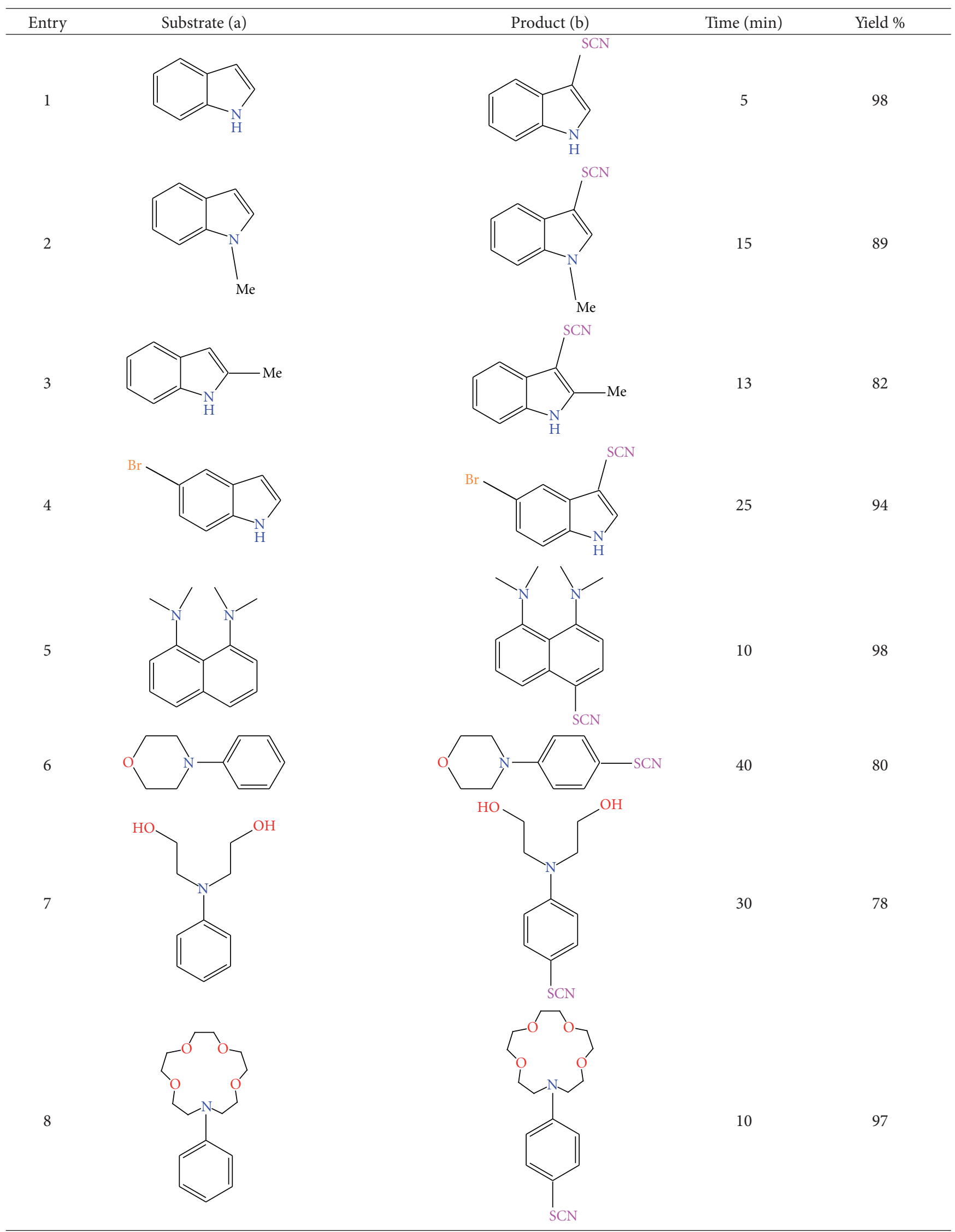


TABLE 2: Continued.

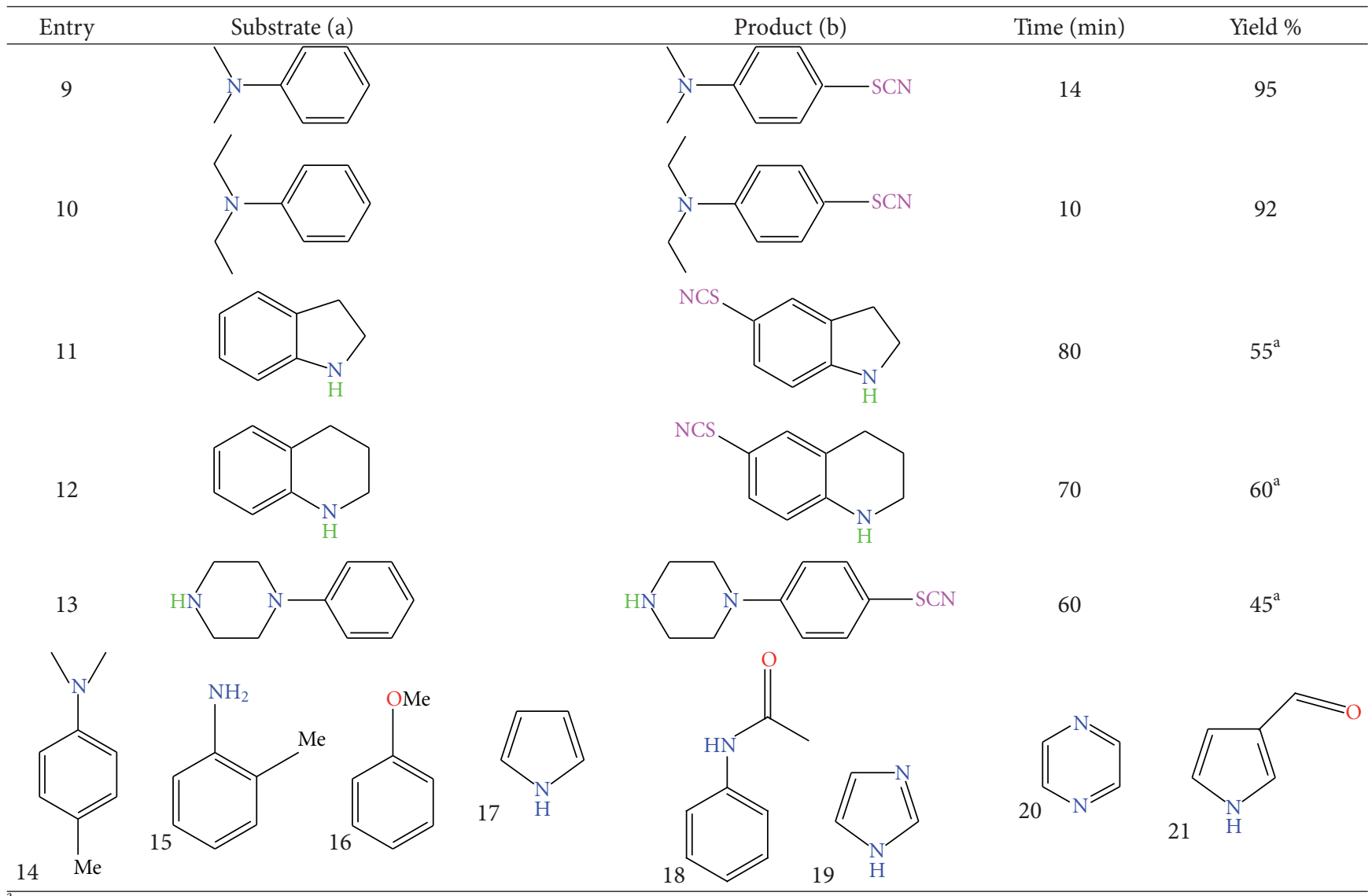

This reactions were not complete (determined by TLC).

\section{Acknowledgments}

The authors gratefully acknowledge partial support of this work by Payame Noor University (PNU) of Ilam. They thank Professor Dr. Marijan Kočevar (Faculty of Chemistry and Chemical Technology, University of Ljubljana) for the very helpful comments on this paper.

\section{References}

[1] R. G. Guy, The Chemistry of Cyanates and Their Thio Derivatives, Edited by S. Patai, John Wiley \& Sons, New York, NY, USA, 1977.

[2] J. S. Yadav, B. V. S. Reddy, S. Shubashree, and K. Sadashiv, "Iodine/MeOH: a novel and efficient reagent system for thiocyanation of aromatics and heteroaromatics," Tetrahedron Letters, vol. 45, no. 14, pp. 2951-2954, 2004.

[3] J. L. Wood, Inorganic Reactions, vol. 3 of Edited by R. Adams, chapter 6, John Wiley \& Sons, New York, NY, USA, 1946.

[4] T. Billard, B. R. Langlois, and M. Medebielle, "Tetrakis(dimethylamino)ethylene (TDAE) mediated addition of difluoromethyl anions to heteroaryl thiocyanates. A new simple access to heteroaryl-SCF $2 \mathrm{R}$ derivatives," Tetrahedron Letters, vol. 42, no. 20, pp. 3463-3465, 2001.

[5] T. Nguyen, M. Rubinstein, and C. Wakselman, "Reaction of perfluoroalkyl carbanions with thiocyanates. Synthesis of fluorinated sulfides and sulfenyl chlorides," Journal of Organic Chemistry, vol. 46, no. 9, pp. 1938-1940, 1981.
[6] T. Billard, S. Large, and B. R. Langlois, "Preparation of trifluoromethyl sulfides or selenides from trifluoromethyl trimethylsilane and thiocyanates or selenocyanates," Tetrahedron Letters, vol. 38, no. 1, pp. 65-68, 1997.

[7] P. A. Grieco, Y. Yokoyama, and E. J. Williams, "Aryl selenocyanates and aryl thiocyanates: reagents for the preparation of activated esters," Organic Chemistry, vol. 43, no. 3, pp. 1283-1285, 1978.

[8] Z. H. Zhang and L. S. Liebeskind, "Palladium-catalyzed, copper(I)-mediated coupling of boronic acids and benzylthiocyanate. A cyanide-free cyanation of boronic acids," Organic Letters, vol. 8, no. 19, pp. 4331-4333, 2006.

[9] R. Riemschneider, F. Wojahn, and G. Orlick, "Thiocarbamates. III. ${ }^{1}$ Aryl thiocarbamates from Aryl thiocyanates," Journal of the American Chemical Society, vol. 73, no. 12, pp. 5905-5907, 1951.

[10] Y. T. Lee, S. Y. Choi, and Y. K. Chung, "Microwave-assisted palladium-catalyzed regioselective cyanothiolation of alkynes with thiocyanates," Tetrahedron Letters, vol. 48, no. 32, pp. 5673-5677, 2007.

[11] H. R. Memarian, I. Mohammadpoor-Baltork, and K. Nikoofar, "Ultrasound-assisted thiocyanation of aromatic and heteroaromatic compounds using ammonium thiocyanate and DDQ," Ultrasonics Sonochemistry, vol. 15, no. 4, pp. 456-462, 2008.

[12] E. Soderback, "Über katalytische Rhodanierung von aromatischen Kernen," Acta Chemica Scandinavica, vol. 8, pp. 1851-1858, 1954. 
[13] A. B. Angus and R. G. R. Bacon, "Thiocyanogen chloride. Part I. Chemical evidence for the existence of the monomeric compound in solutions in organic solvents," Journal of the Chemical Society, pp. 774-778, 1958.

[14] S. Uemura, M. Okano, and K. Ichikawa, "The reaction of arylthallium(III) compounds with copper(II) and (I) thiocyanates," Bulletin of the Chemical Society of Japan, vol. 46, no. 10, pp. 3254-3257, 1973.

[15] S. Uemura, A. Onoe, H. Okazaki, and M. Okano, "Aromatic thiocyanation by a mixture of antimony(V) chloride and lead(II) thiocyanate," Bulletin of the Chemical Society of Japan, vol. 48, no. 2, pp. 619-620, 1975.

[16] Y. Kita, T. Takada, S. Mihara, B. A. Whelan, and H. Tohma, "Novel and direct nucleophilic sulfenylation and thiocyanation of phenol ethers using a hypervalent iodine (III) reagent," The Journal of Organic Chemistry, vol. 60, no. 22, pp. 7144-7148, 1995.

[17] A. Khazaei, A. Alizadeh, and R. G. Vaghei, "Preparation of arylthiocyanates using $\mathrm{N}, N^{\prime}$-dibromo-N, $N^{\prime}$-bis(2, 5-dimethylbenzenesulphonyl) ethylenediamine and N,N-dibromo-2,5dimethylbenzenesulphonamide in the presence of $\mathrm{KSCN}$ as a novel thiocyanating reagent," Molecules, vol. 6, no. 3, pp. 253-257, 2001.

[18] M. S. Grant and H. R. Snyder, "Thiocyanation of indole. Some reactions of 3-thiocyanoindole," Journal of the American Chemical Society, vol. 82, no. 11, pp. 2742-2744, 1960.

[19] F. D. Toste, V. D. Stefano, and I. W. Still, "A versatile procedure for the preparation of Aryl thiocyanates using Nthiocyanatosuccinimide (NTS) a versatile procedure for the preparation of Aryl thiocyanates using N-thiocyanatosuccinimide (NTS)," Synthetic Communications, vol. 25, no. 8, pp. 1277-1286, 1995.

[20] V. Nair, T. G. George, L. G. Nair, and S. B. Panicker, "A direct synthesis of aryl thiocyanates using cerium(IV) ammonium nitrate," Tetrahedron Letters, vol. 40, no. 6, pp. 1195-1196, 1999.

[21] M. Chakrabarty and S. Sarkar, "A clay-mediated eco-friendly thiocyanation of indoles and carbazoles," Tetrahedron Letters, vol. 44, no. 44, pp. 8131-8133, 2003.

[22] G. Wu, Q. Liu, Y. Shen, W. Wu, and L. Wu, "Regioselective thiocyanation of aromatic and heteroaromatic compounds using ammonium thiocyanate and oxone," Tetrahedron Letters, vol. 46, no. 35, pp. 5831-5834, 2005.

[23] N. Iranpoor, H. Firouzabadi, D. Khalili, and R. Shahin, "A new application for diethyl azodicarboxylate: efficient and regioselective thiocyanation of aromatics amines," Tetrahedron Letters, vol. 51, no. 27, pp. 3508-3510, 2010.

[24] N. Iranpoor, H. Firouzabadi, and R. Azadi, "A new diphenylphosphinite ionic liquid $\left(\mathrm{IL}-\mathrm{OPPh}_{2}\right)$ as reagent and solvent for highly selective bromination, thiocyanation or isothiocyanation of alcohols and trimethylsilyl and tetrahydropyranyl ethers," Tetrahedron Letters, vol. 47, no. 31, pp. 5531-5534, 2006.

[25] A. Kumar, P. Ahamd, and R. A. Maurya, "Direct $\alpha$ thiocyanation of carbonyl and $\beta$-dicarbonyl compounds using potassium peroxydisulfate-copper(II)," Tetrahedron Letters, vol. 48, no. 8, pp. 1399-1401, 2007.

[26] A. Khazaei, M. A. Zolfigol, M. Mokhlesi, F. D. Panah, and S. Sajjadifar, "Simple and highly efficient catalytic thiocyanation of aromatic compounds in aqueous media," Helvetica Chimica Acta, vol. 95, no. 1, pp. 106-114, 2012.

[27] C. J. Li and T. H. Chan, Organic Reactions in Aqueous Media, John Wiley \& Sons, New York, NY, USA, 1997.
[28] P. A. Grieco, Organic Synthesis in Water, Thomson Science, Glasgow, Scotland, 1998.

[29] C. Li, "Organic reactions in aqueous media with a focus on carbon-carbon bond formations: a decade update," Chemical Reviews, vol. 105, no. 8, pp. 3095-3166, 2005.

[30] B. P. Bandgar, P. E. More, V. T. Kamble, and J. V. Totre, "Synthesis of polyhydroquinoline derivatives under aqueous media," Arkivoc, vol. 2008, no. 15, pp. 1-8, 2008.

[31] M. M. Heravi, B. Baghernejad, and H. A. Oskooie, "Organic synthesis in water: a green protocol for the synthesis of 2(cyclohexylamino)-3- aryl- indeno[1,2-b]furan-4-ones," Molecular Diversity, vol. 13, no. 3, pp. 385-387, 2009.

[32] A. R. Kiasat and M. Fallah-Mehrjardi, " $\mathrm{B}\left(\mathrm{HSO}_{4}\right)_{3}$ : a novel and efficient solid acid catalyst for the regioselective conversion of epoxides to thiocyanohydrins under solvent-free conditions," Journal of the Brazilian Chemical Society, vol. 19, no. 8, pp. 1595-1599, 2008.

[33] X. Q. Pan, M. Y. Lei, J. P. Zou, and W. Zhang, "Mn(OAc) ${ }_{3}^{-}$ promoted regioselective free radical thiocyanation of indoles and anilines," Tetrahedron Letters, vol. 50, no. 3, pp. 347-349, 2009.

[34] T. Tuttle, J. Cerkovnik, J. Koller, and B. Plesničar, “The search for protonated dihydrogen trioxide $(\mathrm{HOOOH})$ : insights from theory and experiment," Journal of Physical Chemistry A, vol. 114, no. 30, pp. 8003-8008, 2010. 

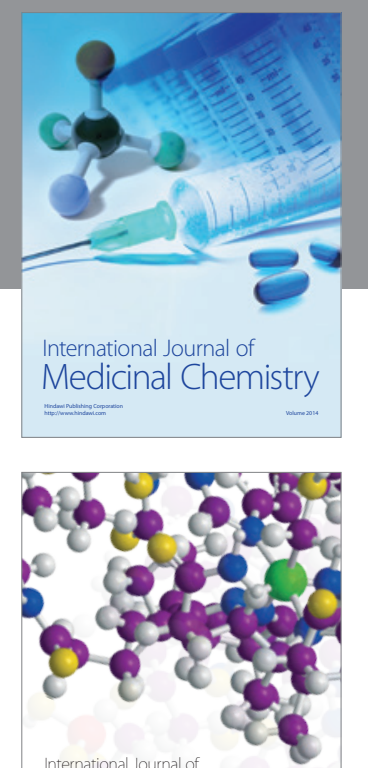

\section{Carbohydrate} Chemistry

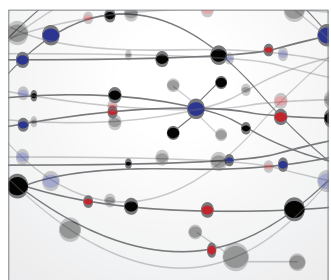

The Scientific World Journal
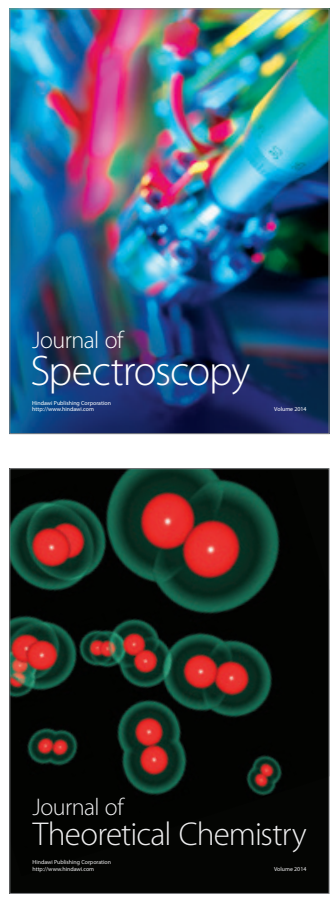
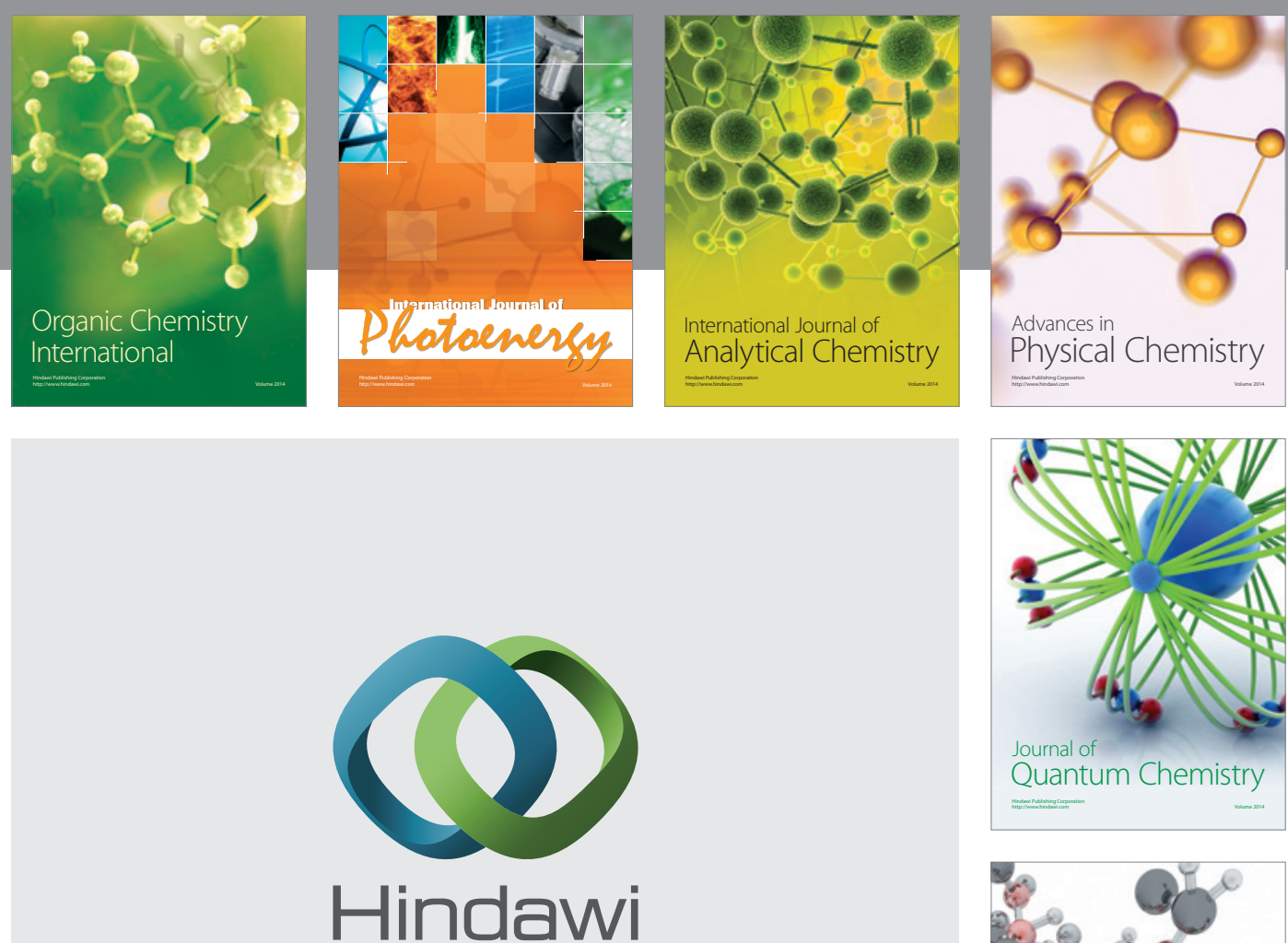

Submit your manuscripts at

http://www.hindawi.com

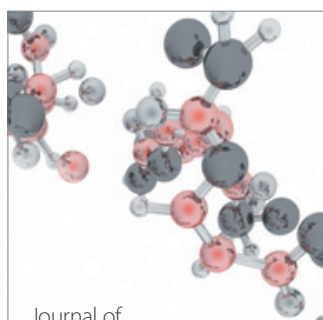

Analytical Methods

in Chemistry

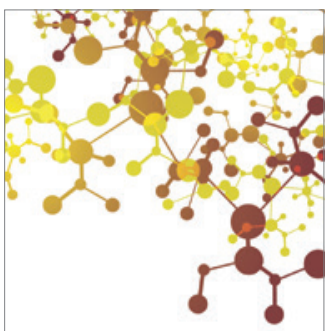

Journal of

Applied Chemistry

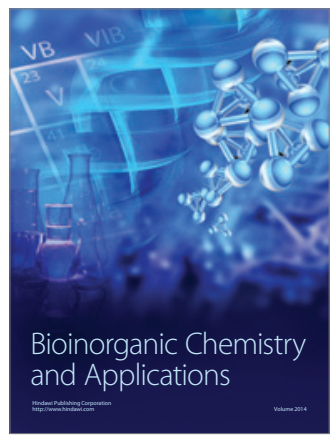

Inorganic Chemistry
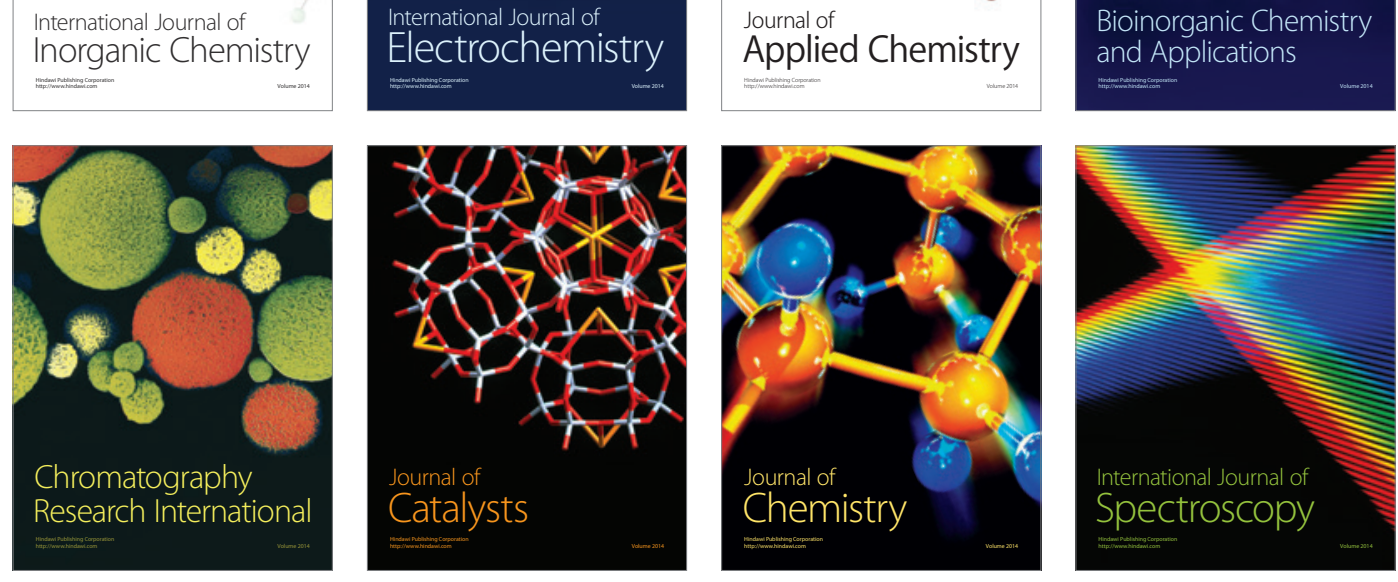